Research Article

\title{
Inserting Stress Analysis of Combined Hexagonal Aluminum Honeycombs
}

\author{
Xiangcheng Li, Kang Li, Yuliang Lin, Rong Chen, and Fangyun Lu \\ College of Science, National University of Defense Technology, Changsha, Hunan 410073, China \\ Correspondence should be addressed to Yuliang Lin; ansen_liang@163.com
}

Received 9 May 2016; Revised 14 August 2016; Accepted 25 August 2016

Academic Editor: Yuri S. Karinski

Copyright (C) 2016 Xiangcheng Li et al. This is an open access article distributed under the Creative Commons Attribution License, which permits unrestricted use, distribution, and reproduction in any medium, provided the original work is properly cited.

\begin{abstract}
Two kinds of hexagonal aluminum honeycombs are tested to study their out-of-plane crushing behavior. In the tests, honeycomb samples, including single hexagonal aluminum honeycomb (SHAH) samples and two stack-up combined hexagonal aluminum honeycombs (CHAH) samples, are compressed at a fixed quasistatic loading rate. The results show that the inserting process of $\mathrm{CHAH}$ can erase the initial peak stress that occurred in SHAH. Meanwhile, energy-absorbing property of combined honeycomb samples is more beneficial than the one of single honeycomb sample with the same thickness if the two types of honeycomb samples are completely crushed. Then, the applicability of the existing theoretical model for single hexagonal honeycomb is discussed, and an area equivalent method is proposed to calculate the crushing stress for nearly regular hexagonal honeycombs. Furthermore, a semiempirical formula is proposed to calculate the inserting plateau stress of two stack-up CHAH, in which structural parameters and mechanics properties of base material are concerned. The results show that the predicted stresses of three kinds of two stackup combined honeycombs are in good agreement with the experimental data. Based on this study, stress-displacement curve of aluminum honeycombs can be designed in detail, which is very beneficial to optimize the energy-absorbing structures in engineering fields.
\end{abstract}

\section{Introduction}

Aluminum honeycombs are composed of numerous open cells which are made of thin aluminum panels. They are orthotropic in different directions, whose cells are in various geometries such as hexagon, triangle, and rectangle. Regular hexagonal honeycombs are most widely used in several vital engineering fields including traffic, aircraft, and aerospace [1]. There are many studies concerning the mechanical properties of aluminum honeycombs from experiments [2-6] and numerical simulations [7-11]. Furthermore, the crushing stress of aluminum honeycombs has been also investigated experimentally and theoretically. According to the existing literatures, works related to crushing stress mainly focus on three aspects: (a) the crushing stress in quasistatic out-ofplane crushing behavior of aluminum honeycombs [12-15]; (b) the crushing stress in dynamic out-of-plane crushing behavior of aluminum honeycombs [16-20]; (c) the stress properties in in-plane mechanical behavior of aluminum honeycombs [21-23].
The out-of-plane crushing stress of aluminum honeycombs under quasistatic loading was investigated theoretically. McFarland [12] firstly deduced a theoretical model to estimate the out-of-plane crushing plateau stress of honeycombs. The parameters were discussed which could determine the crushing stress and the crushing stress results with the parameters varying. It was also available with experimental verification. Then, Wierzbicki and Abramowicz [13] proposed an optimized model based on the energy balance to predict the crushing plateau stress. It showed that two-thirds of energy was used in inextensional deformations and the remaining part was dissipated through extensional deformations. It proved that the method could fit the existing experimental data well. Besides, Wierzbicki [14] also provided a method with a minimum principle in plasticity. It was equivalent to these folding elements undergoing extensional deformations and bending for hexagonal structures. Gibson and Ashby [15] also presented a formula to analysis the mechanics of honeycombs crush under different types of loading, including combined loading and axial one. 


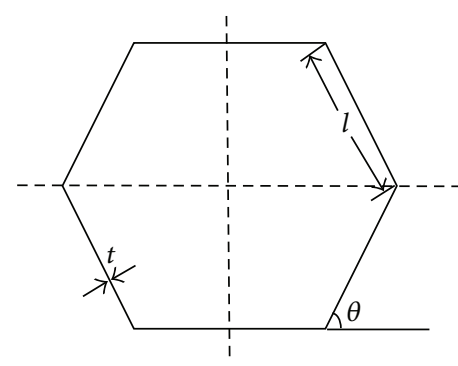

(a)
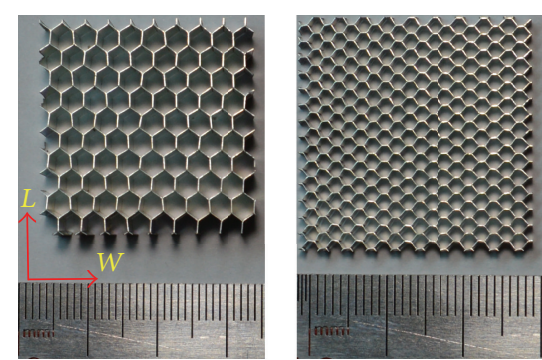

(b)

Figure 1: Two kinds of honeycombs applied in tests. (a) Honeycomb cell structure and (b) $\mathrm{H} 1\left(l_{d 1}=1.87 \mathrm{~mm}\right)$ and $\mathrm{H} 2\left(l_{d 2}=1.13 \mathrm{~mm}\right)$.

The dynamic out-of-plane crushing stress of aluminum honeycombs was mainly studied from experimental aspects. $\mathrm{Xu}$ et al. [16] studied four types of aluminum honeycombs at a constant compressive velocity. They concluded that the crushing stress was linearly related to the specimen dimensions and presented a semiempirical formula, which described the effects of the relative density and the strain rate on stress. Yamashita and Gotoh [17] analyzed compressive stress of aluminum honeycombs by experimental methods. They thought the stress was the combination of the crushing stress and air pressure, and the air pressure could not be ignored with the increase of impact velocity. Baker et al. [18] considered that the crushing stress of honeycombs would be affected by strain-rate effect. They verified it by conducting experiments at $2000 \mathrm{~s}^{-1}$ with aluminum and stainless steel honeycombs. Experimental results indicated both honeycombs showed this effect. Zhao et al. [19] used SHPB (Split Hopkinson Pressure Bar [20]) to impact the samples of aluminum honeycombs. The impact speed reached $50 \mathrm{~ms}^{-1}$ and they thought that the microinertia effect was an important factor on sensitivity of the stress.

Moreover, some experimental and simulated studies about in-plane mechanical behavior of aluminum honeycombs were reported. Khan et al. [21] investigated the inplane crushing properties of aluminum honeycombs with Digital Image Correlation (DIC). Ruan et al. [22] studied in-plane dynamic behavior of honeycombs by finite element simulation. They concluded that dynamic plateau stress was higher than the static value, which was explained by shock wave theory. Zhao et al. [23] got the same conclusion as well.

Above all, most researchers have focused on the compressive property of single hexagonal aluminum honeycomb (SHAH). In this work, we are going to investigate the mechanical property of two stack-up combined honeycombs, which involves the inserting interaction between two honeycomb samples [1]. For studying the inserting property of combined aluminum honeycombs in detail, this work aims at proposing a semiempirical formula, which can predict the inserting plateau stress of combined hexagonal aluminum honeycombs $(\mathrm{CHAH})$. Firstly, quasistatic tests of SHAH and $\mathrm{CHAH}$ samples are carried out to investigate the out-of-plane compressive properties. Secondly, an equivalent model based on the existing formula [13] is constructed to calculate the crushing plateau stress of SHAH. Thirdly, a semiempirical formula is proposed to predict the inserting plateau stress of $\mathrm{CHAH}$, in which the shear strength of base material of honeycombs and cell structure parameters are concerned.

\section{Quasistatic Experimental Arrangement}

2.1. Materials and Specimens. The material tested in this work is a standard commercial honeycomb, whose structure is hexagonal. Honeycomb cell structure is illustrated in Figure 1(a), in which $t$ is wall thickness of a cell, $l$ is length of a side, and $\theta$ is $60^{\circ}$. The based material is Al5052 aluminum alloy. Poisson's ratio is 0.33 . The yield stress $\sigma_{0}$ is $163 \mathrm{MPa}$ and Young's modulus $E$ is $69 \mathrm{GPa}$. There are two types of honeycombs in size, as shown in Figure 1(b). One is with the designed dimension of $l_{d 1}=1.87 \mathrm{~mm}$ and $t=0.05 \mathrm{~mm}$; the other is with $l_{d 2}=1.13 \mathrm{~mm}$ and $t=0.05 \mathrm{~mm}$. To distinguish the two honeycombs clearly, $\mathrm{H} 1\left(l_{d 1}=1.87 \mathrm{~mm}\right)$ and $\mathrm{H} 2$ $\left(l_{d 2}=1.13 \mathrm{~mm}\right)$ are named in the following description.

In the tests, the specimens are processed into cuboids by wire-cut electrical discharge machining. Their uniform size in the $L-W$ plane is $30 \mathrm{~mm}$ by $30 \mathrm{~mm}$. The thickness in the axial compressive direction is designed as $10 \mathrm{~mm}$ for SHAH. Two SHAH samples are stacked into a CHAH sample, whose total thickness in the axial compression direction is $20 \mathrm{~mm}$. There are three groups of specimens for $\mathrm{CHAH}$, which are H1$10 \mathrm{~mm}+\mathrm{H} 1-10 \mathrm{~mm}, \mathrm{H} 2-10 \mathrm{~mm}+\mathrm{H} 2-10 \mathrm{~mm}$, and H1-10 mm + H2-10 mm. Besides, some samples of single honeycomb, marked as H1-20 mm and H2-20 mm, are designed to compare the differences of energy-absorbing property between single honeycomb sample and combined honeycomb sample with the same thickness. It is noted that the same thickness in the axial direction of double honeycombs for $\mathrm{CHAH}$ is a simplest combination, which is in favor of studying the interaction of CHAH theoretically.

2.2. Test Setup. The quasistatic axial crushing tests are carried out on a material testing machine at room temperature, as shown in Figure 2. In the tests, the loading speed is controlled at $2.0 \mathrm{~mm}$ per minute. Load-displacement curves are recorded by a computer-operated data acquisition system. Furthermore, the testing process is shot by a camera in each test. A ruler is used to help value the displacement in the pictures. For two stacked honeycombs' sample (as shown 


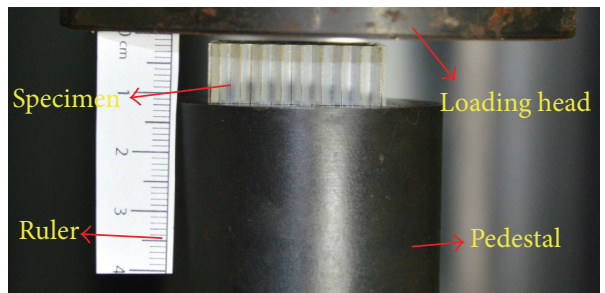

(a)

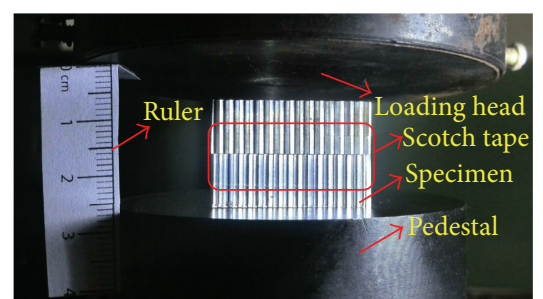

(b)

FIGURE 2: Installation setup in testing. (a) SHAH and (b) CHAH.

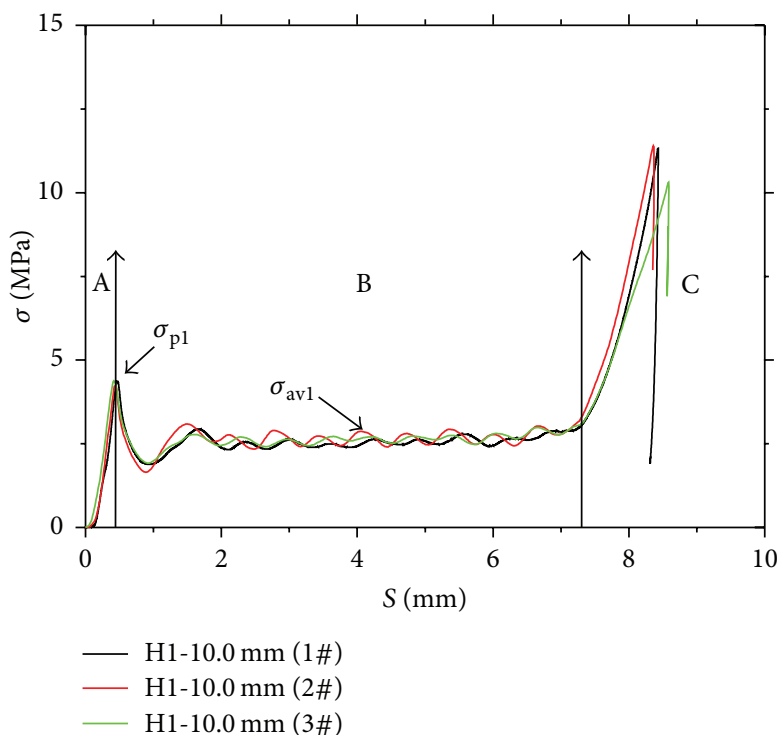

(a)

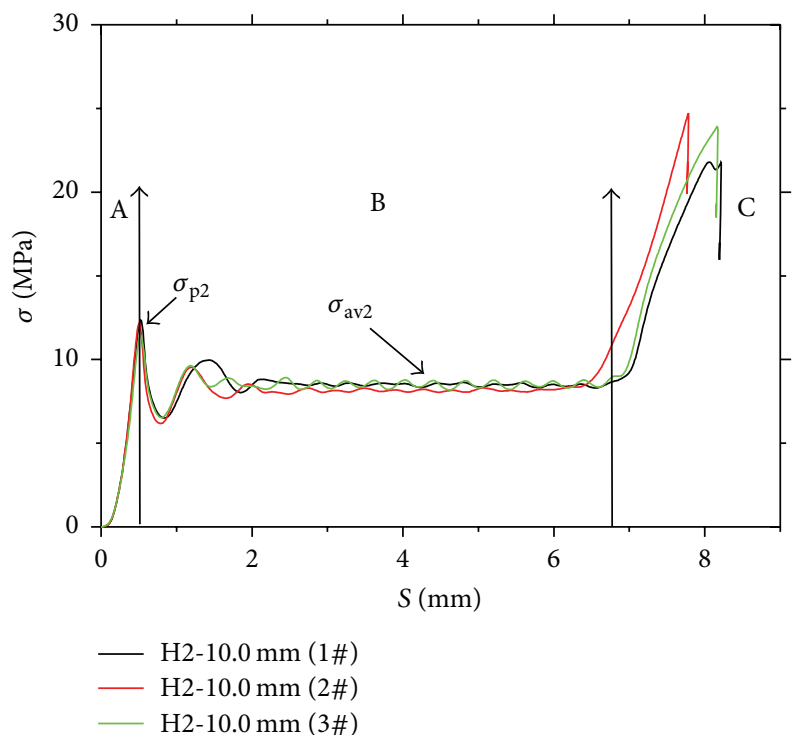

(b)

Figure 3: Compressive mechanical responses of SHAH. (a) H1 and (b) H2.

in Figure 2(b)), a scotch tape is used to fix the two single honeycomb specimens. The influence of scotch tape is not considered in this study because its strength is very low.

\section{Experimental Results}

3.1. Mechanical Responses of SHAH. For two types of aluminum honeycombs $\mathrm{H} 1$ and $\mathrm{H} 2$, different groups of experiments are conducted. Three concordant stress-displacement curves are attained for each group. The stress-displacement curves are shown in Figure 3. From the figure, one can see that the three testing curves are in good correspondence with each other and the crushing trend for the other two groups of specimens is similar.

Taking $\mathrm{H1}-10 \mathrm{~mm}$ as an example, its typical curve is divided into three parts (A, B, and C). Part A is approximately a linear elastic region. There is an initial peak stress in this part, the average of which is $4.330 \mathrm{MPa}$. In most cases, initial peak stress is unfavorable to the buffered property of aluminum honeycombs. Part B is a crushing plateau, which contributes most of the total displacement. This part plays a key role in the energy absorption. For H1-10 mm specimens, the average crushing plateau stress is $2.593 \mathrm{MPa}$. Part C
TABLE 1: Initial peak stress and the crushing stress of SHAH.

\begin{tabular}{lccccc}
\hline Group & Stress & 1\# & 2\# & 3\# & Average \\
\hline \multirow{2}{*}{ H1-10 mm } & $\sigma_{p 1}[\mathrm{MPa}]$ & 4.376 & 4.233 & 4.381 & 4.330 \\
& $\sigma_{\text {av1 }}[\mathrm{MPa}]$ & 2.522 & 2.639 & 2.618 & 2.593 \\
\hline \multirow{2}{*}{$\mathrm{H} 2-10 \mathrm{~mm}$} & $\sigma_{p 2}[\mathrm{MPa}]$ & 12.356 & 12.160 & 11.441 & 11.986 \\
& $\sigma_{\mathrm{av} 2}[\mathrm{MPa}]$ & 8.514 & 8.155 & 8.492 & 8.387 \\
\hline
\end{tabular}

corresponds to a densification response of SHAH when the strain is high. As a result, the stress parameters of $\mathrm{H1}-10 \mathrm{~mm}$ and $\mathrm{H} 2-10 \mathrm{~mm}$ are listed in Table 1.

3.2. Mechanical Responses of CHAH. For CHAH, three groups of experiments are carried out using material testing machine. Similarly, three curves are obtained for each group of combined samples, as shown in Figure 4. The curves of different groups are also in good correspondence with each other.

Taking H1-10 mm + H1-10 mm as an example, the typical response can be divided into five parts (A, B, C, D, and E), as shown in Figure 4(a). Furthermore, the pictures of four 


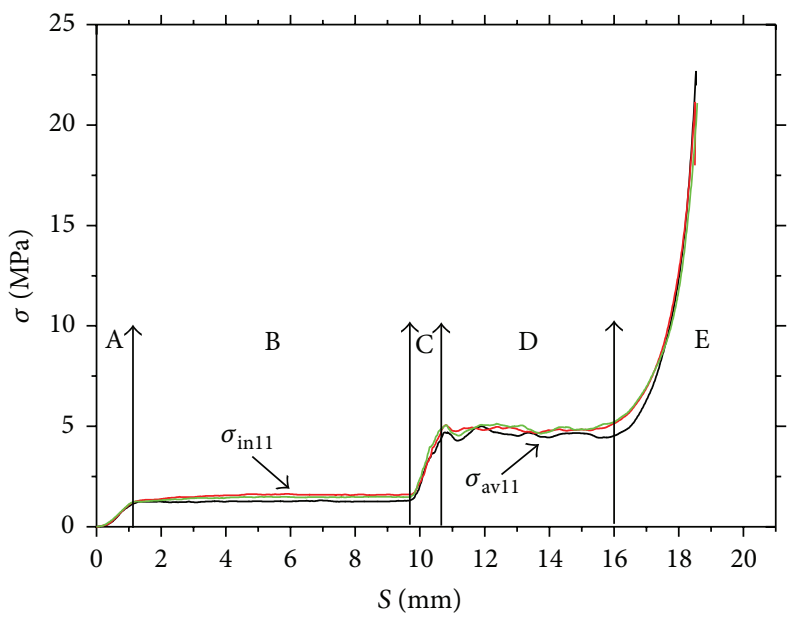

H1-10.0 mm + H1-10.0 mm (1\#)
H1-10.0 mm + H1-10.0 mm (2\#)
H1-10.0 mm + H1-10.0 mm (3\#)

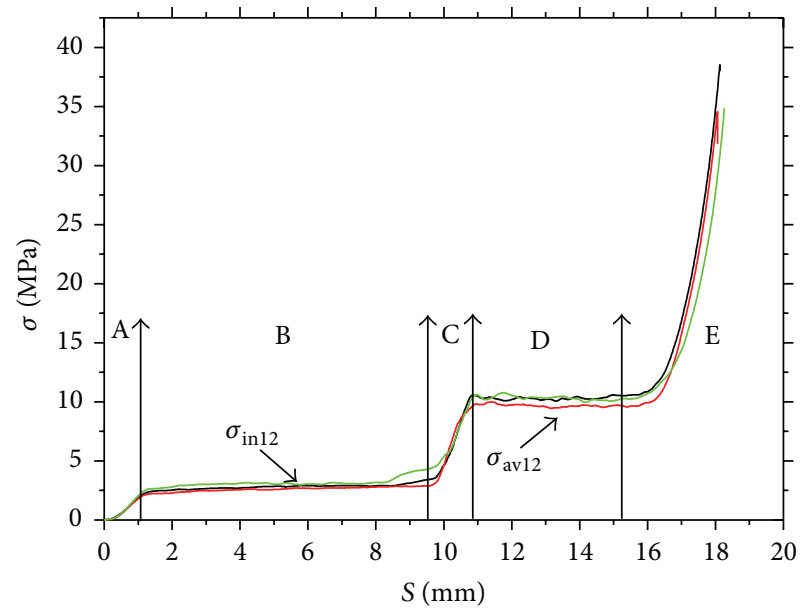

H1-10.0 mm + H2-10.0 mm (1\#)

- H1-10.0 mm + H2-10.0 mm (2\#)

H1-10.0 mm + H2-10.0 mm (3\#)

(a)

(b)

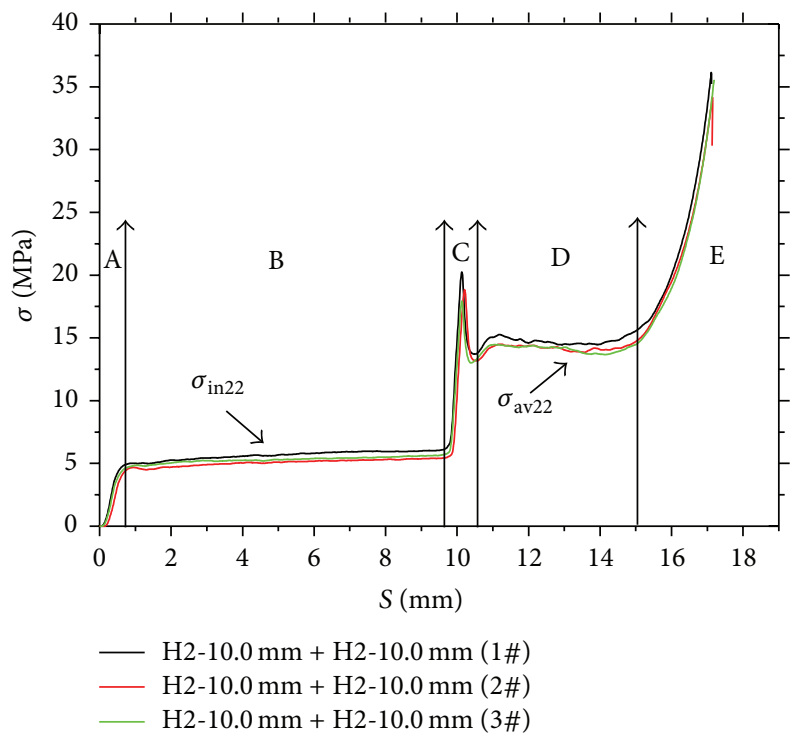

(c)

Figure 4: Compressive mechanical curves of two stack-up CHAH samples. (a) H1-10 mm + H2-10 mm, (b) H1-10 mm + H2-10 mm, and (c) $\mathrm{H} 2-10 \mathrm{~mm}+\mathrm{H} 2-10 \mathrm{~mm}$.

typical moments in the H1-10 mm + H1-10 mm compressive process are shown in Figure 5. Among the five parts, Part A corresponds to an initial linear elastic regime, which is approximately in accordance with the status in Figure 5(a). From Figure 4(a), the conclusion can be obtained that the initial peak stress $\left(\sigma_{p 1}\right.$ in Figure 3(a)) does not occur in the part. It is a simplified way to erase initial peak stress in practical applications although the honeycomb is precrushed initially in general. Part B is a plateau of two honeycomb specimens inserted into each other, which is corresponding to the status in Figure 5(b). Comparing Figures 3(a) and 4(a), one can see that inserting plateau stress of $\mathrm{CHAH}$ is lower than crushing plateau stress of SHAH. Part C corresponds to linear elastic region of total inserting combined honeycomb specimens (as in Figure 5(c)). Part D is an extended plastic plateau of the combined honeycombs, fitted with the status in Figure 5(d), in which the combined specimen is compacted gradually. Part E is the last period which corresponds to the densification process at high strain of the $\mathrm{CHAH}$. The displacement of densification reaches $15.858 \mathrm{~mm}$ (or crushed strain reaches 0.793 ).

The parameters of inserting stress (Part B), crushing stress (Part D), and densification displacement are listed in Table 2. Furthermore, as indicated in Figure 5(b), the inserting stress $\sigma_{\text {in11 }}$ of $\mathrm{H} 1-10 \mathrm{~mm}+\mathrm{H} 1-10 \mathrm{~mm}$ comes from shear action between the cells. Comparing Tables 1 and 2, one can see that the inserting stress is obviously lower than the crushing stress for the same honeycomb. Once the stack-up honeycombs are 


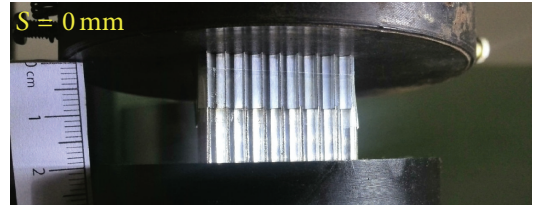

(a)

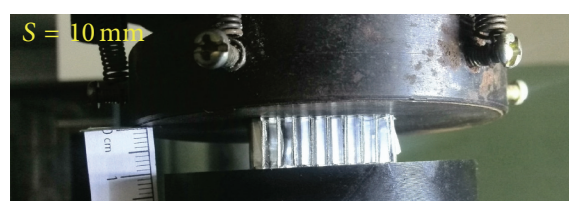

(c)

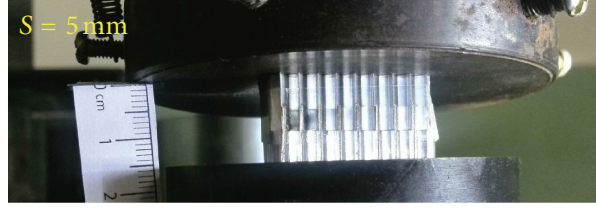

(b)

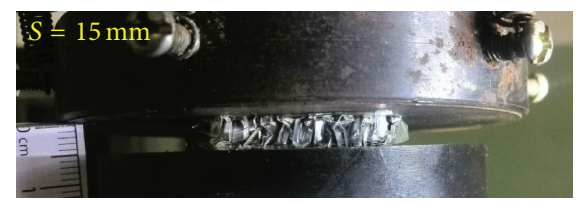

(d)

FIgURE 5: Typical compressive deformation of two stack-up CHAH samples (H1-10 $\mathrm{mm}+\mathrm{H1}-10 \mathrm{~mm})$ in the axial direction. (a) $S=0 \mathrm{~mm}$, (b) $S=5 \mathrm{~mm}$, (c) $S=10 \mathrm{~mm}$, and (d) $S=15 \mathrm{~mm}$.

TABLE 2: Compressive parameters of two stack-up CHAH.

\begin{tabular}{|c|c|c|c|c|c|}
\hline Group & Parameters & $1 \#$ & $2 \#$ & $3 \#$ & Average \\
\hline \multirow{3}{*}{$\mathrm{H} 1-10 \mathrm{~mm}+\mathrm{H} 1-10 \mathrm{~mm}$} & $\sigma_{\text {in } 11}[\mathrm{MPa}]$ & 1.260 & 1.556 & 1.447 & 1.421 \\
\hline & $\sigma_{\mathrm{av} 11}[\mathrm{MPa}]$ & 4.645 & 4.831 & 4.917 & 4.798 \\
\hline & Densification displacement [mm] & 16.015 & 15.755 & 15.805 & 15.858 \\
\hline \multirow{3}{*}{$\mathrm{H} 2-10 \mathrm{~mm}+\mathrm{H} 2-10 \mathrm{~mm}$} & $\sigma_{\text {in22 }}[\mathrm{MPa}]$ & 5.633 & 5.049 & 5.285 & 5.322 \\
\hline & $\sigma_{\mathrm{av} 22}[\mathrm{MPa}]$ & 14.703 & 14.191 & 14.109 & 14.334 \\
\hline & Densification displacement [mm] & 15.065 & 15.003 & 14.963 & 15.010 \\
\hline \multirow{3}{*}{$\mathrm{H} 1-10 \mathrm{~mm}+\mathrm{H} 2-10 \mathrm{~mm}$} & $\sigma_{\text {in } 12}[\mathrm{MPa}]$ & 2.822 & 2.624 & 3.032 & 2.826 \\
\hline & $\sigma_{\mathrm{av} 12}[\mathrm{MPa}]$ & 10.395 & 9.710 & 10.260 & 10.122 \\
\hline & Densification displacement [mm] & 16.090 & 16.120 & 16.068 & 16.093 \\
\hline
\end{tabular}

inserted entirely, the residual structure can be considered as a new type of honeycombs. The crushing stress $\left(\sigma_{\mathrm{av} 11}, \sigma_{\mathrm{av} 22}\right.$, and $\sigma_{\text {av12 }}$ ) of the new honeycomb still remains a plateau.

In order to obtain more details about the inserting process, the whole model of $\mathrm{CHAH}$ sample was constructed by use of ANSYS. Then, a picture of top view is shown in Figure 6(a), and an amplifying picture is shown in Figure 6(b). Moreover, two pictures of vertical section cut-out view of the insertion are presented in Figure $6(\mathrm{c})(S=0 \mathrm{~mm})$ and Figure 6(d) $(S=5 \mathrm{~mm})$, which can indicate the inserting process between the top and bottom samples more easily.

In addition, two " $Y$ " models with a semiperspective drawing are conducted (ratio of transparency of the top sample is $70 \%$ and that of the bottom sample is $0 \%$ ), in which there are typical interaction states between two stackup samples, as illustrated in Figure 7. The green " $Y$ " model is a corner among three hexagonal cells of the top sample. The red one is corresponding part of the bottom sample. Both the top honeycomb cell walls and bottom honeycomb cell walls are cut partially because they have the same material and thickness. Taking CHAH sample of H1-H1 as an example, according to the simulated results of ANSYS, inserting depth of each honeycomb sample is about half (50\%) of the total inserting displacement, just as shown in Figure 7. In the actual experiments, the conclusion is similar, though a few other random occasions occur due to inhomogeneity of base material or the difference of cell structure.

\section{Inserting Stress Analysis}

4.1. Crushing Plateau Stress of SHAH. Based on Wierzbicki's theory [13], the quasistatic out-of-plane plateau stress of regular hexagonal honeycombs can be calculated as

$$
\sigma_{\mathrm{av}}=6.6 \sigma_{0}\left(\frac{t}{l}\right)^{5 / 3}
$$

where $\sigma_{\mathrm{av}}$ is average crushing stress of the honeycomb and $\sigma_{0}$ is yield stress of the base material. $t$ and $l$ are wall thickness and side length of a cell, respectively, as shown in Figure 1(a).

In the process of aluminum honeycombs manufacture, the thickness in the axial compressive direction can be controlled accurately, while the dimensions of a cell in the $L-W$ plane are difficult to be controlled exactly. For the two types of aluminum honeycombs used in this work, the designed side lengths of the cells are $1.87 \mathrm{~mm}$ and $1.13 \mathrm{~mm}$, which are provided by the manufacturer. According to the designed sizes, the average crushing stress $\sigma_{\text {avd }}$ of $\mathrm{H} 1$ and $\mathrm{H} 2$ can be calculated using (1), as listed in Table 3. The calculated result of $\mathrm{H} 1$ is consistent with the experimental data, while the result of $\mathrm{H} 2$ is not in harmony with experimental result well. After checking the aluminum honeycomb specimens carefully, we found some cells are not exactly regular hexagonal cells, especially for $\mathrm{H} 2$. 


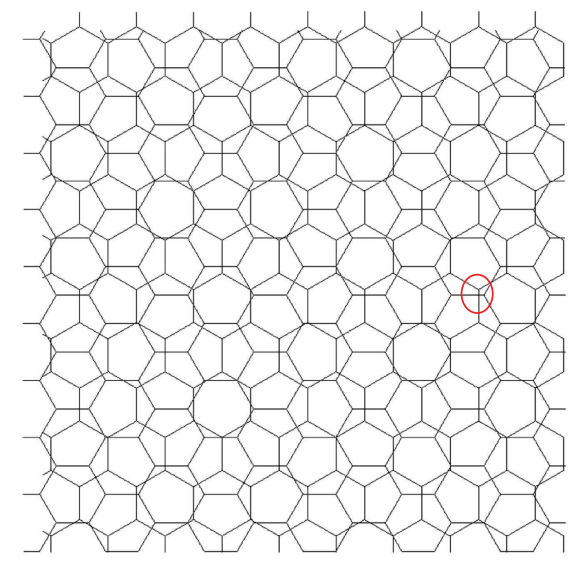

(a)

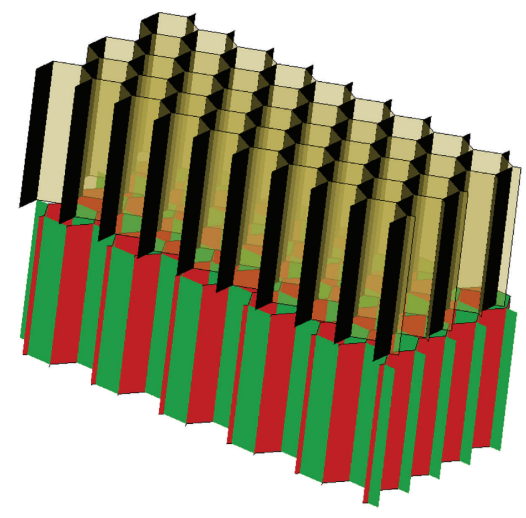

(c)

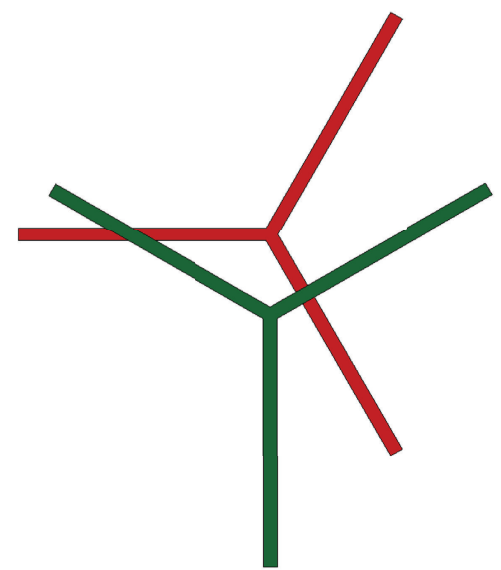

(b)

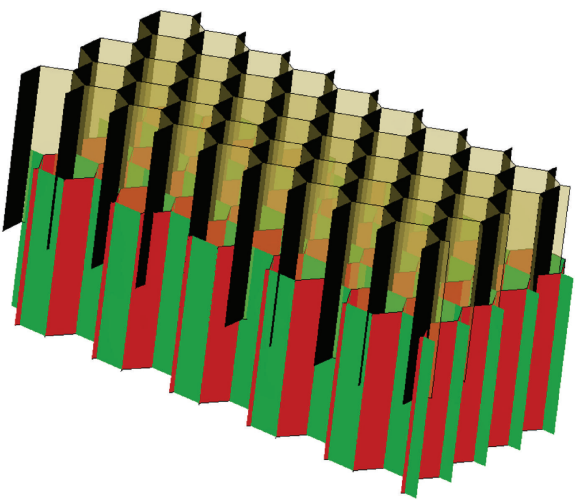

(d)

FIgURE 6: Schematic of CHAH sample of top view and vertical section cut-out view. (a) Top view; (b) amplification of the red circle area in (a); (c) partial section view with $S=0 \mathrm{~mm}$; (d) partial section view with $S=5 \mathrm{~mm}$.

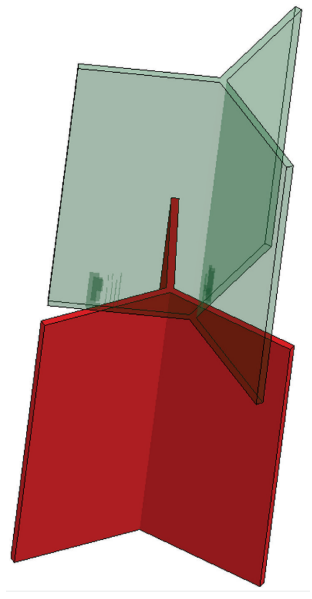

(a)

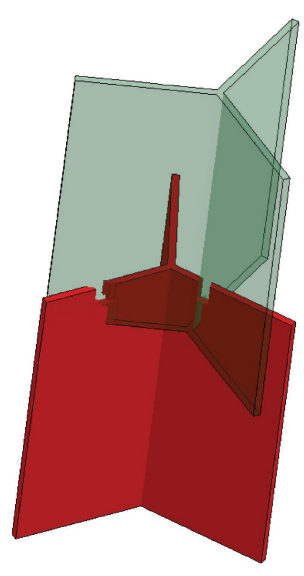

(b)

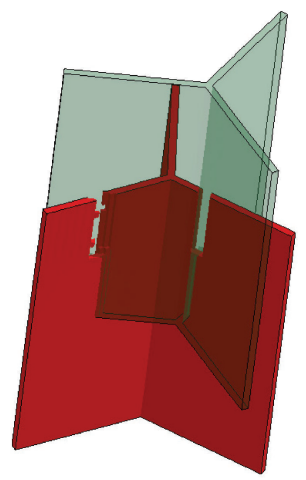

(c)

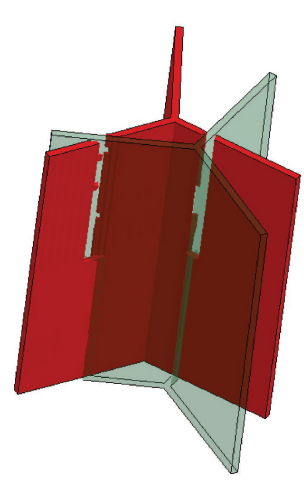

(d)

FIGURE 7: Semiscenogram of "Y" model for inserting process between the top and bottom samples. (a) $S=0 \mathrm{~mm}$; (b) $S=2 \mathrm{~mm}$; (c) $S=5 \mathrm{~mm}$; (d) $S=10 \mathrm{~mm}$. 
TABLE 3: Parameters of $\mathrm{H} 1$ and $\mathrm{H} 2$ about the equivalent method.

\begin{tabular}{lcccccc}
\hline Type & $\begin{array}{c}\text { Designed size } l_{d} \\
{[\mathrm{~mm}]}\end{array}$ & $\begin{array}{c}\text { Equivalent size } \\
l_{e}[\mathrm{~mm}]\end{array}$ & $\begin{array}{c}\text { Counted } \\
\text { cell number }\end{array}$ & $\begin{array}{c}\text { Designed } \\
\sigma_{\text {avd }}[\mathrm{MPa}]\end{array}$ & $\begin{array}{c}\text { Experimental } \\
\sigma_{\mathrm{av}}[\mathrm{MPa}]\end{array}$ & $\begin{array}{c}\text { Equivalent } \\
\sigma_{\text {ave }}[\mathrm{MPa}]\end{array}$ \\
\hline $\mathrm{H} 1$ & 1.870 & 1.843 & 102 & 2.569 & 2.593 & 2.635 \\
$\mathrm{H} 2$ & 1.130 & 1.076 & 299 & 5.916 & 8.387 & 6.458 \\
\hline
\end{tabular}

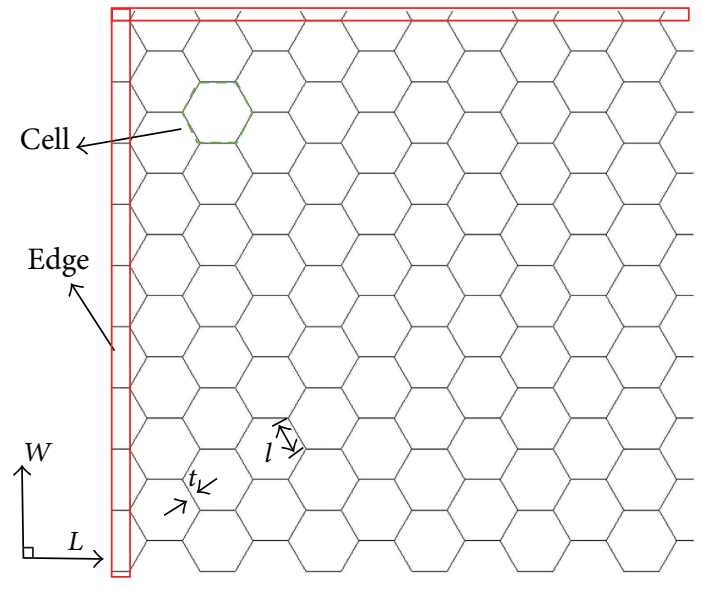

FIGURE 8: Equivalent cells for nearly regular hexagonal honeycombs.

In order to correct the calculated results, an equivalent method is used in the paper, in which the geometry configuration of all cells is regarded as regular hexagon exactly, as shown in Figure 8. In the equivalent process, numbers of the cells in each aluminum honeycomb specimens are counted one by one. For the edge area (as in Figure 8), halfbaked cell is regarded as half of a whole cell approximately (i.e., 0.5 in counted number). Then, the average numbers of equivalent regular cells are 102 for $\mathrm{H} 1$ specimens and 299 for $\mathrm{H} 2$ specimens. Therefore, equivalent areas of single regular hexagon cell are $8.823 \mathrm{~mm}^{2}$ for $\mathrm{H1}$ and $3.010 \mathrm{~mm}^{2}$ for $\mathrm{H} 2$. According to area calculating formula $3 \sqrt{3} l^{2} / 2$, the equivalent lengths of a cell are $l_{e 1}=1.843 \mathrm{~mm}$ for $\mathrm{H1}$ and $l_{e 2}=1.076 \mathrm{~mm}$ for H2. Substituting the parameters into (1), the average crushing stress $\sigma_{\text {ave }}$ of $\mathrm{H} 1$ and $\mathrm{H} 2$ can be obtained. All the results are listed in Table 3.

As indicated in Figure 1(b), $\mathrm{H} 1$ is more regular than $\mathrm{H} 2$. Therefore, for regular hexagonal honeycomb H1, both $\sigma_{\text {avd }}$ and $\sigma_{\text {ave }}$ are in keeping with the experimental result $\sigma_{\mathrm{av}}$. The conclusion also shows that (1) is only suitable for calculating crushing stress of regular hexagonal honeycomb. For irregular hexagonal honeycomb $\mathrm{H} 2$, the average crushing stress $\sigma_{\text {ave }}$ of $\mathrm{H} 2$ is still different from experimental data (relative error is $22.99 \%)$. However, the calculated precision increases $6.47 \%$ (original relative error is about 29.46\%). Therefore, it is accessible that the equivalent method is extended to calculate the crushing stress for the practical honeycombs which are nearly regular hexagonal structure.

4.2. Inserting Plateau Stress of CHAH. As illustrated in Figure 5, the inserting process of $\mathrm{CHAH}$ specimens indeed is that cell walls of different specimens are inserted into each other. Therefore, inserting stress is positively correlated with overlap area of the two stack-up CHAH specimens [1]. However, the overlap area is determined by the geometric structural parameters of honeycomb. Structures with the smaller cell size correspond to larger contacting region. For hexagonal aluminum honeycombs, $t$ and $l$ are main structural parameters. In addition, just as the discussion in Section 3.2, the inserting mechanical behavior is caused by shear action between cell walls; hence, the inserting stress is also related to shear strength of base material. Furthermore, according to the form of (1) in Section 4.1, a semiempirical formula about the inserting stress of two stack-up CHAH specimens is proposed as follows:

$$
\sigma_{\text {in }}=\alpha \cdot \sigma_{s} \cdot\left(\frac{t_{1}}{l_{e 1}} \cdot \frac{t_{2}}{l_{e 2}}\right)^{\beta},
$$

where $\alpha$ is a correlative coefficient of interaction; $\beta$ is a structural coefficient of honeycombs; $t_{1}, l_{e 1}$ and $t_{2}, l_{e 2}$ are cell equivalent structural parameters of two honeycombs, respectively; $\sigma_{s}$ is shear stress of base material. In the engineering applications, shear stress generally is set as about $55 \%$ of the yield stress [24]. For the aluminum honeycomb used in this work, shear stress $\sigma_{s}$ is $90 \mathrm{MPa}$. In addition, the equivalent lengths $l_{e 1}$ and $l_{e 2}$ (as listed in Table 3 ) are used to increase the applicability of (2).

The coefficients $\alpha$ and $\beta$ can be obtained based on the three groups of experimental results. For the three groups of tests, three standard variance curves of inserting stress to structural coefficient $\beta$ are plotted in Figure 9. Based on the principle of minimum standard variance, the minimum standard variance occurs in the curve of $\mathrm{H} 2-\mathrm{H} 2$ and the coefficient $\beta=1.2024$. According to the experimental results of $\mathrm{H} 2-\mathrm{H} 2$, the coefficients $\alpha$ can be calculated, which is 95.223. As a result, (2) may be shown in the following form:

$$
\sigma_{\text {in }}=95.223 \sigma_{s}\left(\frac{t_{1}}{l_{e 1}} \cdot \frac{t_{2}}{l_{e 2}}\right)^{1.2024} .
$$

In order to verify the precision of the formula, the inserting stresses calculated using (3) and experimental values for $\mathrm{H} 1-\mathrm{H} 1, \mathrm{H} 2-\mathrm{H} 2$, and $\mathrm{H} 1-\mathrm{H} 2$ are listed in Table 4. The least standard variance of the three groups of inserting stresses is 0.0316 , which shows that the semiempirical formula is reasonable for predicting inserting stress of two stack-up $\mathrm{CHAH}$ samples.

According to (1) and (3), for the same honeycomb structure, the ratio of the crushing plateau stress in SHAH and inserting stress in $\mathrm{CHAH}$ can be calculated as

$$
\frac{\sigma_{\text {in }}}{\sigma_{\mathrm{av}}} \approx \frac{95.223}{6.6} \frac{\sigma_{s}}{\sigma_{0}}\left(\frac{t}{l}\right)^{0.738} \text {. }
$$


TABLE 4: Inserting stress of $\mathrm{H} 1$ and $\mathrm{H} 2$.

\begin{tabular}{lccc}
\hline Type & $\sigma_{\text {in11 }}[\mathrm{MPa}]$ & $\sigma_{\text {in22 }}[\mathrm{MPa}]$ & $\sigma_{\text {in12 }}[\mathrm{MPa}]$ \\
\hline Experimental value & 1.421 & 5.322 & 2.826 \\
Calculated value & 1.459 & 5.322 & 2.786 \\
\hline
\end{tabular}

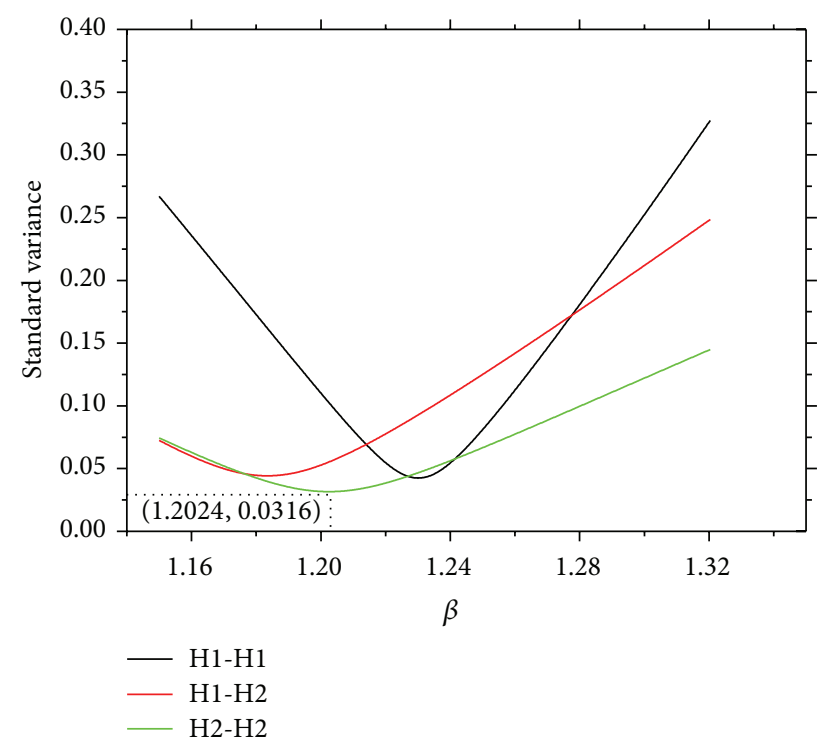

FIGURE 9: Standard variation of the inserting stress into structural coefficient $\beta$ in three curves.

Then, the ratio of inserting stress $\sigma_{\text {in }}$ and the crushing plateau stress $\sigma_{\mathrm{av}}$ is about 0.55 for $\mathrm{H} 1$ and about 0.80 for $\mathrm{H} 2$, which are consistent with the experimental results approximately.

4.3. Discussion. In the two sections above, the equivalent structural parameters were calculated to modify the crushing stress of SHAH and a new semiempirical formula was proposed to predict the inserting stress of $\mathrm{CHAH}$. The predicted results are in harmony with experimental data. Meanwhile, the form of the formula is simply and accessible, in which structural parameters and shear properties of base material are both considered. In this section, some details on crushing and energy-absorbing property of $\mathrm{CHAH}$ are discussed and the application of (3) is analyzed.

The compressive stress-displacement curves of two groups of aluminum honeycomb samples with thickness of $20 \mathrm{~mm}$ are shown in Figure 10(a). As in the figure, it is noted that the insertion process can erase the initial peak stress that occurred in the compression of SHAH, which is a more simplified way in practical applications than the way of precrushing the honeycomb to erase the initial peak stress. However, the collapse stress significantly increases when the two stacked specimens with the same thickness are inserted into each other (as $\mathrm{H} 2-10 \mathrm{~mm}+\mathrm{H} 2-10 \mathrm{~mm}$ in Figure 10(a)). The phenomenon can be eliminated when two different thickness honeycomb samples are stacked [1]. In this work, the phenomenon is not discussed in detail because it does not influence the analysis of inserting stress.
Furthermore, the absorbed energy of the two groups of aluminum honeycomb samples is illustrated in Figure 10(b). The absorbed energy corresponds to the area integral under the different curve (as in Figure 10(a)). The upper displacement limit of integral is densification displacement. For H1-20 mm and H1-10 mm + H1-10 mm, the displacements are $14.150 \mathrm{~mm}$ and $16.005 \mathrm{~mm}$, respectively. For H2$20 \mathrm{~mm}$ and $\mathrm{H} 2-10 \mathrm{~mm}+\mathrm{H} 2-10 \mathrm{~mm}$, they are $13.670 \mathrm{~mm}$ and $15.098 \mathrm{~mm}$. As in Figure 10(b), one can see that buffering property of CHAH sample is better than that of SHAH sample with the same honeycomb construction and the same sample thickness if the two honeycomb samples are crushed completely. The energy-absorbing parameters of different honeycomb samples are listed in Table 5. In the table, the insertion energy corresponds to the area integral when the two honeycomb samples are inserted into each other entirely (the displacement is $10 \mathrm{~mm}$ ).

As shown in Table 5, energy-absorbing property of $\mathrm{CHAH}$ sample is also more advantageous than that of SHAH sample if the two honeycomb samples are crushed completely. In fact, once the two honeycombs are crushed completely, respectively, the total absorbed energy for $\mathrm{CHAH}$ is more than that for SHAH $(42.240 \mathrm{MPa} * \mathrm{~mm}>37.900 \mathrm{MPa} * \mathrm{~mm}$ for $\mathrm{H} 1$ and $123.757 \mathrm{MPa} * \mathrm{~mm}>95.597 \mathrm{MPa} * \mathrm{~mm}$ for $\mathrm{H} 2$ ). In addition, for $\mathrm{CHAH}$ sample, main part of the absorbed energy is contributed by the second crushing plateau period after two stack-up honeycomb samples are inserted into each other entirely. The proportion of the inserting process in absorbed energy is less than the later crushing process of CHAH (31.9\% for $\mathrm{H} 1$ and $41.8 \%$ for $\mathrm{H} 2$ ).

Besides, it should be noted that there are some limits about the semiempirical formula (3). Firstly, the geometry configuration of honeycombs is regular hexagon. For irregular hexagon honeycombs, it is accessible to deal with the irregular structure to regular hexagon honeycombs using the equivalent method in Section 4.1. However, it is not clear whether the equivalent method can be used to other shape configurations. Secondly, this formula can be only used to predict the inserting stress of the two stack-up honeycombs with the same base material. For the $\mathrm{CHAH}$ with different base materials, further study needs to be done in the following work.

In addition, the crushing plateau stress $\left(\sigma_{\mathrm{av1} 1}, \sigma_{\mathrm{av} 22}\right.$, and $\sigma_{\text {av12 }}$ in Figure 4) of inserted two stack-up honeycombs will be discussed in the following work. A theoretical or semiempirical formula is expected to be proposed; then, the two plateau stresses in the whole curve of two stack-up honeycombs can be predicted.

\section{Conclusion}

Two types of hexagonal aluminum honeycombs were selected to test under quasistatic loading condition. Out-of-plane mechanical property of single aluminum honeycomb and two stack-up aluminum honeycombs were investigated. For each test, three testing curves were obtained in good correspondence with each other. Typical stress-displacement curve of SHAH can be divided into three parts, and typical curve of two stack-up $\mathrm{CHAH}$ can be divided into five parts. The stress 
TABLE 5: Energy-absorbing parameters of different honeycomb samples.

\begin{tabular}{lcccc}
\hline Sample & H1-20 mm & H1-10 mm + H1-10 mm & H2-10 mm & H2-10 mm + H2-10 mm \\
\hline Densification displacement $[\mathrm{mm}]$ & 14.150 & 16.005 & 13.670 & 15.098 \\
Total absorbed energy $[\mathrm{MPa} * \mathrm{~mm}]$ & 37.900 & 42.240 & 95.597 & 123.757 \\
Insertion energy $[\mathrm{MPa} * \mathrm{~mm}]$ & - & 13.490 & - & 51.704 \\
\hline
\end{tabular}

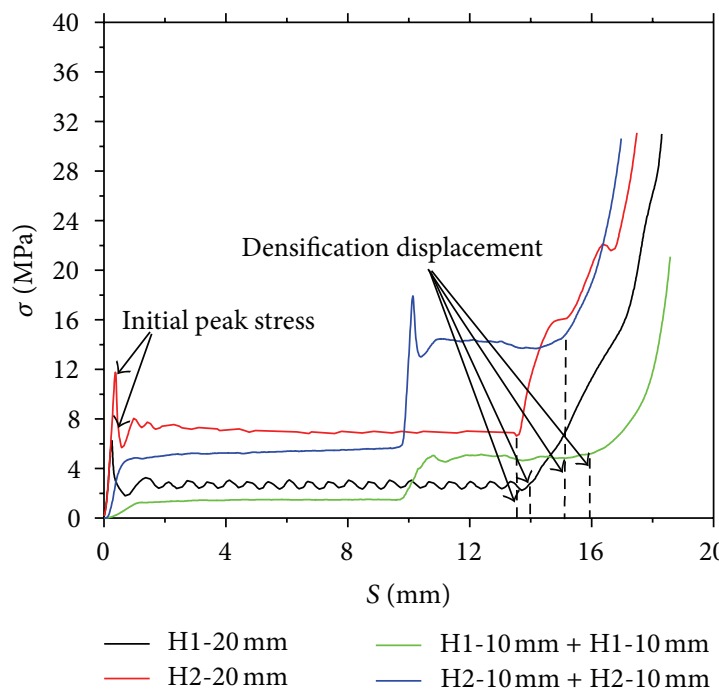

(a)

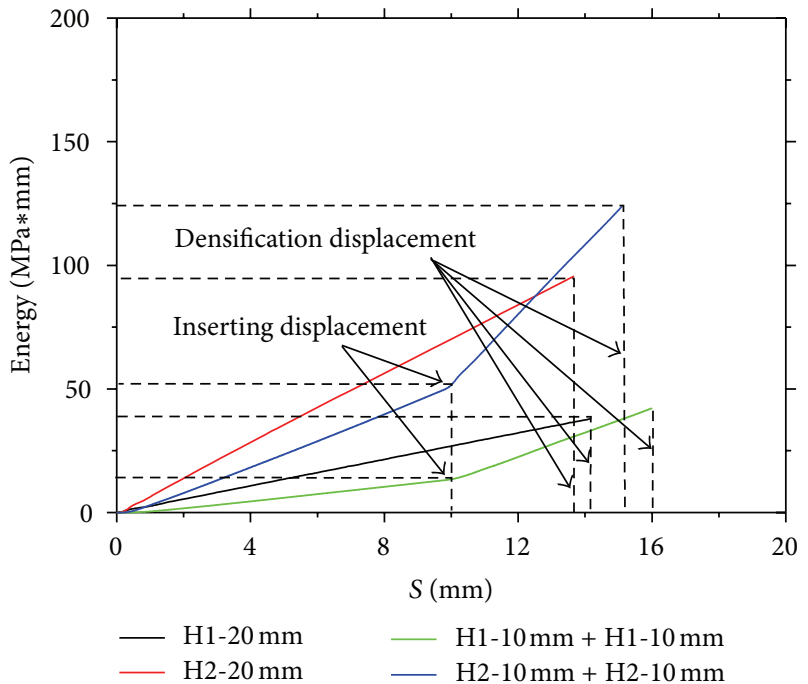

(b)

FIGURE 10: Comparison on the crushing and energy-absorbing property of honeycomb. (a) Crushing property and (b) energy-absorbing property.

of two stack-up CHAH is increased step by step. Based on the existing theoretical model, the crushing stresses of two kinds of single aluminum honeycomb are discussed. Since the cell structure of honeycomb $\mathrm{H} 2$ is not regular hexagon, an area equivalent method is proposed to calculate the hexagon cell size. The equivalent method can provide a new approach to calculate the crushing stress for nearly regular hexagonal honeycombs.

Furthermore, a semiempirical formula was proposed to calculate the inserting plateau stress of two stack-up CHAH, in which structural parameters and mechanics properties of base material were considered. The predicted results are well in agreement with the experimental results. Though there are some limits for the semiempirical formula, we think the study can provide guidance for fine and optimizing buffered and energy-absorbing structure design of combined aluminum honeycombs.

\section{Competing Interests}

The authors declare that there is no conflict of interests regarding the publication of this article.

\section{Acknowledgments}

The authors would like to thank the National Natural Science Foundation of China [Grant no. 11672329 and no. 11132012].

\section{References}

[1] Y.-L. Lin, Z.-F. Zhang, R. Chen, Y. Li, X.-J. Wen, and F.-Y. $\mathrm{Lu}$, "Cushioning and energy absorbing property of combined aluminum honeycomb," Advanced Engineering Materials, vol. 17, no. 10, pp. 1434-1441, 2015.

[2] Z. Wang, G. Gao, H. Tian, and Z. Lu, "A stability maintenance method and experiments for multi-player tandem aluminium honeycomb array," International Journal of Crashworthiness, vol. 18, no. 5, pp. 483-491, 2013.

[3] X. Li, P. Zhang, Z. Wang, G. Wu, and L. Zhao, "Dynamic behavior of aluminum honeycomb sandwich panels under air blast: experiment and numerical analysis," Composite Structures, vol. 108, no. 1, pp. 1001-1008, 2014.

[4] S. T. Hong, J. Pan, T. Tyan, and P. Prasad, "Dynamic crush behaviors of aluminum honeycomb specimens under compression dominant inclined loads," International Journal of Plasticity, vol. 22, no. 6, pp. 1062-1088, 2006.

[5] A. S. M. Ashab, R. Dong, G. X. Lu, and Y. C. Wong, "Quasi-static and dynamic experiments of aluminum honeycombs under combined compression-shear loading," Materials \& Design, vol. 97, pp. 183-194, 2016.

[6] A. Alavi Nia and M. Z. Sadeghi, "An experimental investigation on the effect of strain rate on the behaviour of bare and foamfilled aluminium honeycombs," Materials and Design, vol. 52, pp. 748-756, 2013.

[7] L. Aktay, A. F. Johnson, and B.-H. Kröplin, "Numerical modelling of honeycomb core crush behaviour," Engineering Fracture Mechanics, vol. 75, no. 9, pp. 2616-2630, 2008. 
[8] Z. Wang, H. Tian, Z. Lu, and W. Zhou, "High-speed axial impact of aluminum honeycomb-experiments and simulations," Composites Part B: Engineering, vol. 56, pp. 1-8, 2014.

[9] S. Li, X. Li, Z. Wang, G. Wu, G. Lu, and L. Zhao, "Finite element analysis of sandwich panels with stepwise graded aluminum honeycomb cores under blast loading," Composites Part A: Applied Science and Manufacturing, vol. 80, pp. 1-12, 2016.

[10] A. S. M. A. Ashab, D. Ruan, G. Lu, and A. A. Bhuiyan, "Finite element analysis of aluminum honeycombs subjected to dynamic indentation and compression loads," Materials, vol. 9, no. 3, pp. 162-180, 2016.

[11] X. Zhang, H. Zhang, and Z. Wen, "Experimental and numerical studies on the crush resistance of aluminum honeycombs with various cell configurations," International Journal of Impact Engineering, vol. 66, pp. 48-59, 2014.

[12] R. K. McFarland, "Hexagonal cell structures under postbuckling axial load," AIAA Journal, vol. 1, no. 6, pp. 1380-1385, 1963.

[13] T. Wierzbicki and W. Abramowicz, "On the crushing mechanics of thin-walled structures," Journal of Applied Mechanics, vol. 50, no. 4, pp. 727-734, 1983.

[14] T. Wierzbicki, "Crushing analysis of metal honeycombs," International Journal of Impact Engineering, vol. 1, no. 2, pp. 157-174, 1983.

[15] L. J. Gibson and M. F. Ashby, Cellular Solids, Structural and Properties, Pergamon Press, Oxford, UK, 1988.

[16] S. Xu, J. H. Beynon, D. Ruan, and G. Lu, "Experimental study of the out-of-plane dynamic compression of hexagonal honeycombs," Composite Structures, vol. 94, no. 8, pp. 23262336, 2012.

[17] M. Yamashita and M. Gotoh, "Impact behavior of honeycomb structures with various cell specifications-numerical simulation and experiment," International Journal of Impact Engineering, vol. 32, no. 1-4, pp. 618-630, 2005.

[18] W. E. Baker, T. C. Togami, and J. C. Weydert, "Static and dynamic properties of high-density metal honeycombs," International Journal of Impact Engineering, vol. 21, no. 3, pp. 149-163, 1998.

[19] H. Zhao, I. Elnasri, and S. Abdennadher, "An experimental study on the behaviour under impact loading of metallic cellular materials," International Journal of Mechanical Sciences, vol. 47, no. 4-5, pp. 757-774, 2005.

[20] H. Kolsky, "An investigation of the mechanical properties of materials at very high rates of loading," Proceedings of the Physical Society B, vol. 62, no. 11, pp. 676-700, 1949.

[21] M. K. Khan, T. Baig, and S. Mirza, "Experimental investigation of in-plane and out-of-plane crushing of aluminum honeycomb," Materials Science and Engineering: A, vol. 539, pp. 135142, 2012.

[22] D. Ruan, G. Lu, B. Wang, and T. X. Yu, "In-plane dynamic crushing of honeycombs-a finite element study," International Journal of Impact Engineering, vol. 28, no. 2, pp. 161-182, 2003.

[23] H. Zhao and G. Gary, "Crushing behaviour of aluminium honeycombs under impact loading," International Journal of Impact Engineering, vol. 21, no. 10, pp. 827-836, 1998.

[24] A. T. Tang, F. S. Pan, M. B. Yang, and R. Cheng, "Mechanical properties and microstructure of magnesium-aluminum based alloys containing strontium," Materials Transactions, vol. 49, no. 6, pp. 1203-1211, 2008. 


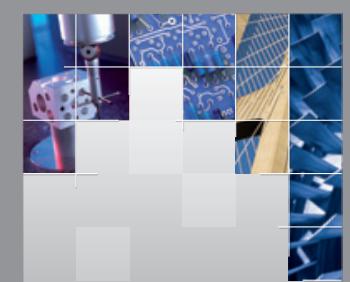

\section{Enfincering}
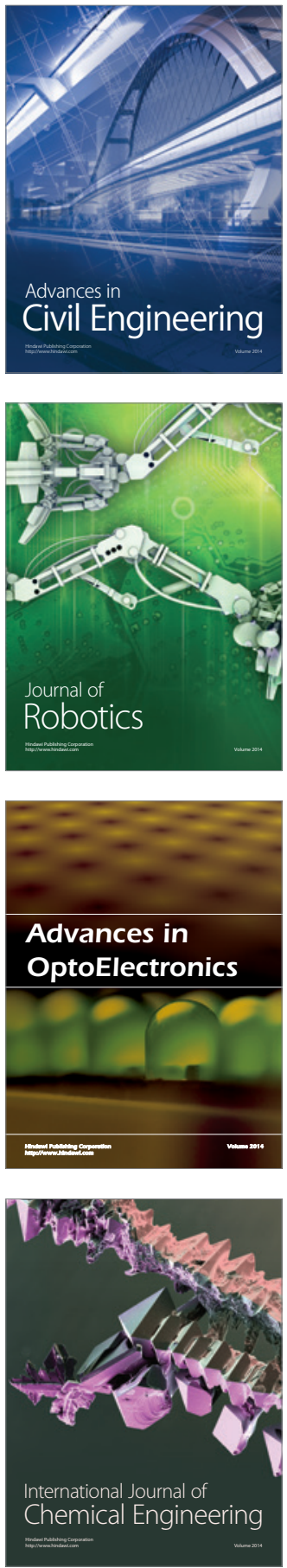

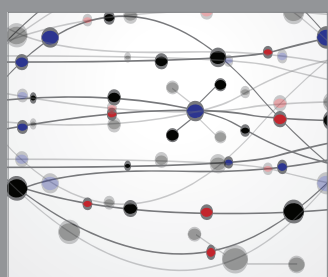

The Scientific World Journal

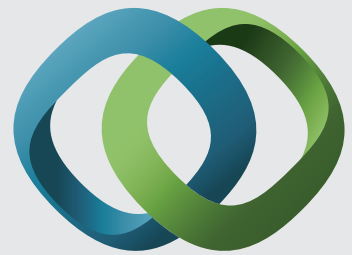

\section{Hindawi}

Submit your manuscripts at

http://www.hindawi.com
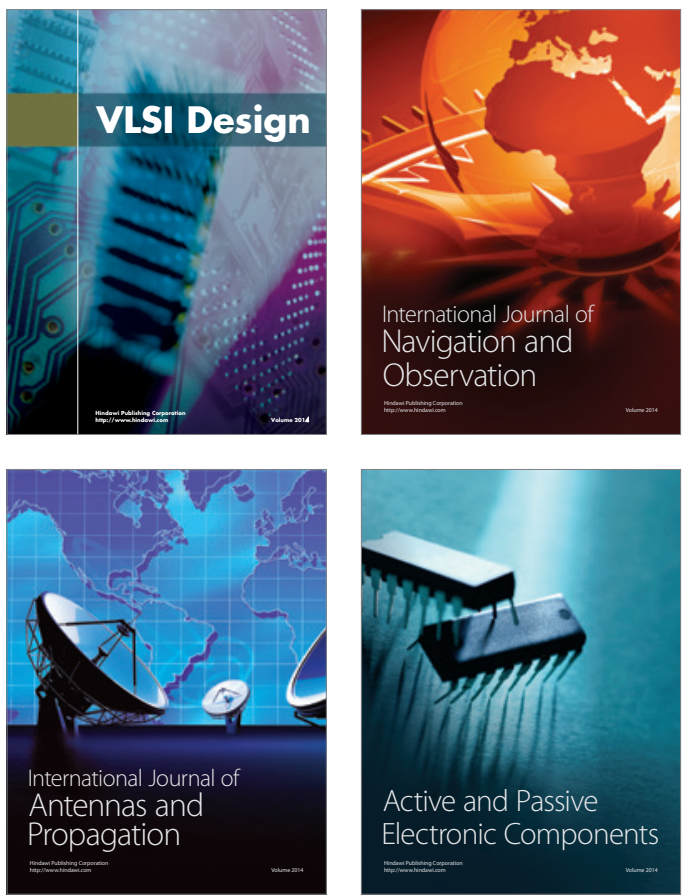
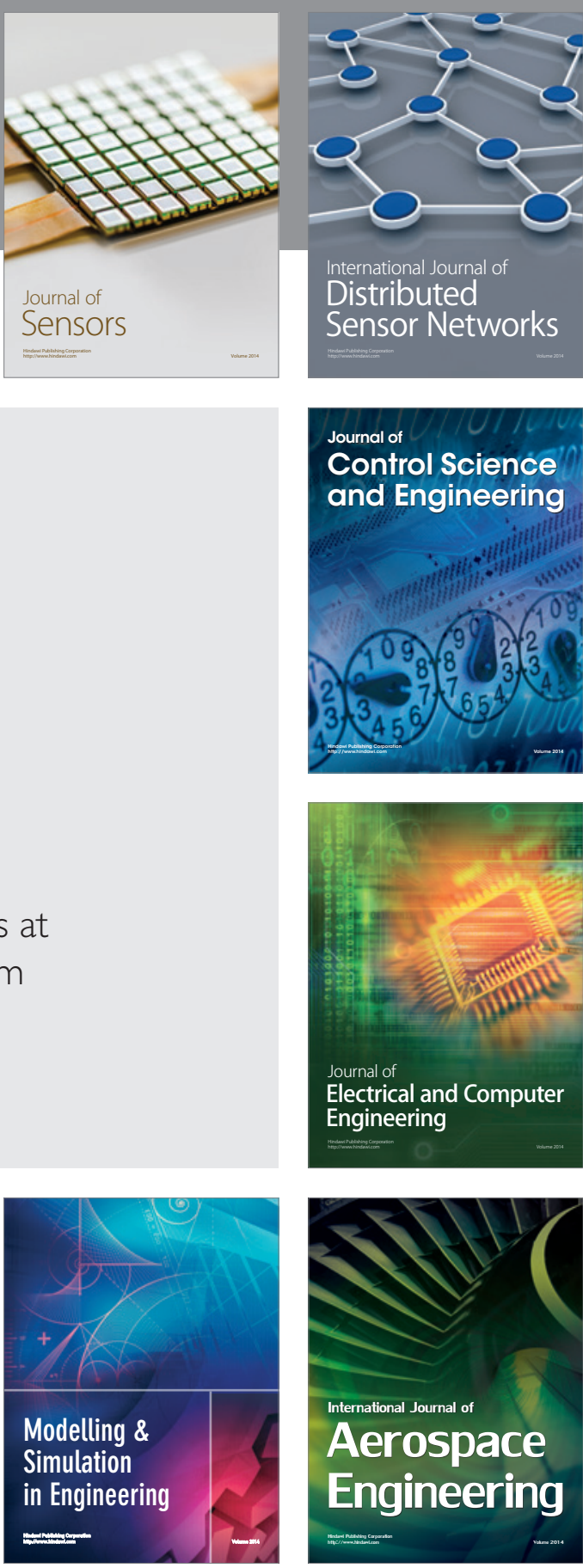

International Journal of

Distributed

Sensor Networks

Journal of

Control Science

and Engineering
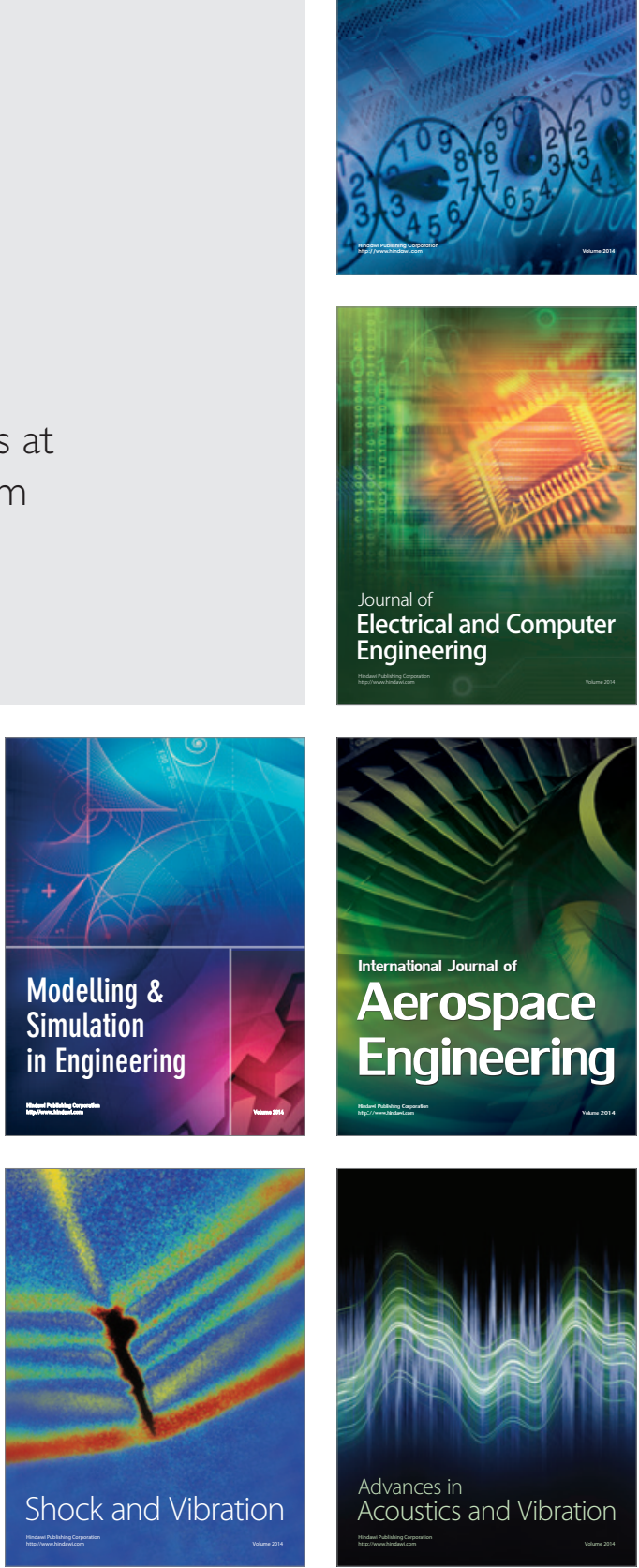